\title{
Açai Fruit as a Source of Bioactive Phytochemicals
}

\author{
Randah M. Alqurashi, Daniel M. Commane and Ian R. Rowland \\ 1. Hugh Sinclair Unit. of Human Nutrition, Department of Food and Nutritional Sciences, University of Reading, Reading RG6 6AP, \\ United Kingdom
}

2. The Saudi Arabian Ministry of Education, Kingdom of Saudi Arabia

\begin{abstract}
The fruit of the açai palm (Euterpe oleracea Mart.) is a rich source of potential bioactive phytochemicals, however neither its precise composition nor the putative benefits to health from its consumption have been fully characterised. This study aims to elucidate the composition of açai fruit pulp and to explore the potential of these extracts to confer protection in a cell culture based model of oxidative DNA damage. Extractions of açai pulps were dissolved in a 80\% methanol (methanol: water, 80: $20 \mathrm{v} / \mathrm{v}$ ) based solvent and the phytochemicals present in the extract were analysing by HPLC detector. Lipids were assessed via GC. The Folin-Ciocalteau assay was used to determine the purposes of providing a phytochemical rich food based comparator with established health benefits. Finally, protection against oxidative DNA damage was assessed in HT-29 cell lines exposed to hydrogen peroxide via the comet assay. Açai pulp extracts were found to be rich in flavonoids, anthocyanins and carotenoids. These extracts were found to protect against oxidative DNA damage (anti-genotoxicity). Açai extracts were more effective at preventing oxidative DNA damage than the blueberry extracts, although their antioxidant capacities as assessed by the FRAP assay were similar. These data shown that açai is a rich source of plant phytochemicals and that these chemicals may protect against oxidative stress in human colon cells (HT-29). Further work is needed to establish the digestive fate of these phytochemicals and to prove the beneficial effects in human.
\end{abstract}

Key words: Açai pulp, antioxidant activity, anti-genotoxicity, polyphenols.

\section{Introduction}

Açai (Euterpe oleracea Mart.) is native to the Amazon basin where its fruit is a popular staple in the diet; it is most often consumed as a dessert or snack blended with other fruits. In recent years açai has appeared in the US and European food markets where consumers associate its consumption with unspecified benefits to health. Traditionally, açai has been used as a natural remedy for a number of disorders, including the treatment of influenza, cold and inflammatory conditions $[1,2]$. As a food, the açai fruit is a good source of energy (81 Kcal/100 g), nutrients, insoluble fiber $(15.0 \mathrm{~g} / 100 \mathrm{~g} \mathrm{DW})$ and protein $(10.3 \mathrm{~g} / 100 \mathrm{~g}$ DW). Moreover, açai is reported to be rich in non-nutritive phenolics, including flavonoids, phenolics and hydroxycinnamic acids, all of which may be biologically active and are suggested to be beneficial to human health [3]. Despite the presence

Corresponding author: Randah M. Alqurashi, research field: food and nutritional sciences. of these potentially bioactive compounds, the effects of consuming them in açai have been poorly characterized $[4,5]$. However, the health benefits of consuming other foods, also rich in similar blends of plant polyphenols, have been well studied; these include established antioxidant, anti-cancer and anti-inflammatory benefits [6-9]. Açai is often marketed towards the health-conscious consumer, exploiting both public assumptions regarding health benefits and compositional characteristics similar to other healthy plant foods, there is however relatively little scientific evidence to substantiate any specific health benefits in human consumers [10].

In this study, we aimed to $i /$ characterize the composition of non-nutritive bioactives present in açai pulp, ii/ to determine the antioxidant capacity of these non-nutritives, and iii/ importantly, to establish protection against oxidative stress in a biological system conferred by the presence of these non-nutritives. We make comparisons with the effects of extracts of blueberry, as blueberry is a well-studied 
berry food with established health benefits $[11,12]$.

\section{Materials and Methods}

\subsection{Chemicals and Reagents}

The solvents used for HPLC and GC were purchased from Fisher Scientific (HPLC grade water, methanol, $\mathrm{HCl}$, formic acid and acetonitrile). Standards for polyphenols, 3,4-dihydroxybenzioic acid, 4-hydroxybenzoic acid, gentisic acid, caffeic acid, syringic acid, chlorogenic acid, salicylic acid, trans-cinnamic acid, kaempferol, vanillic acid, gallic acid, quercetin, ferulic acid, isoferulic acid, p-coumaric acid, sinapic acid, catechin and acerbic acid were obtained from Sigma-Aldrich (UK). Cyanidin-3-O-glucoside, cyanidin-3-O-rutinoside, pelargonidin-3-O-glucoside, delphinidin-3-O-glucoside, malvidin-3-O-glucoside, peonidin-3-glucoside and peonidin-3-rutinoside were obtained from Extrasynthese (Genay, France) as anthocyanin standards for HPLC analysis. Reagents for the assessment of total phenolics and total flavonoids, ferric reducing antioxidant power (FRAP), Folin-Ciocalteu reagent, sodium carbonate, aluminium chloride, sodium nitrite, sodium hydroxide, and sodium acetate trihydrate, glacial acetic acid, 2,4,6-tripyridyl-S-triazin (TPTZ), ferric chloride hexahydrate and ascorbic acid (as standards) were obtained from Sigma-Aldrich. HT-29 cells were obtained from the Department of Food and Nutritional Sciences at the University of Reading.

\subsection{Preparation of Fruit Extracts}

Pure açai pulp was harvested from fully ripe fruit in 2012 and was kindly supplied by Sublime food (UK). Blueberries (Vaccinium corymbosum) were obtained in September, 2012 from a local supermarket in Reading (Berkshire, UK). Samples were prepared as described previously [3]. In brief, açai pulp (100 g) and whole blueberries $(100 \mathrm{~g})$ were freeze-dried upon receipt. Freeze-dried foods are stable against the oxidation process and the powdered form facilitates efficient extraction [13]. The samples were frozen overnight at
$-80{ }^{\circ} \mathrm{C}$ and then dried in an IEC Lyoprep-3000 freeze dryer (Dunstable, UK) for one week before the samples were ground to powder.

All samples were stored at $-20{ }^{\circ} \mathrm{C}$ until further analysis Figure 17. The freeze-dried samples of açai and blueberry ( $0.5 \mathrm{~g}$ in triplicate) were homogenized in $80 \%$ methanol (methanol: water, $80: 20 \mathrm{v} / \mathrm{v}$ ) using a vortex mixer for $5 \mathrm{~min}$ and kept at room temperature

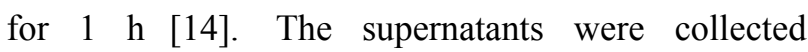
following centrifugation at $1,500 \mathrm{~g}$ for $10 \mathrm{~min}$ at room temperature, before a second and third extraction. The supernatants were pooled and filtered through a $0.45-\mu \mathrm{m}$ filter (sterile) (Fisher Scientific, UK). The extracts were protected from light by foil and used immediately to avoid the oxidation of polyphenols [15].

\subsection{Determination of Total Phenolics}

The total phenolic content was assessed using the Folin-Ciocalteu method [16]. In brief, $5-\mu \mathrm{L}$ aliquots of gallic acid $(0-1,000 \mathrm{mg} / \mathrm{L})$ were prepared as standards and added to the wells of a 96-well plate to obtain data for generating a standard curve, while $5-\mu \mathrm{L}$ aliquots of solvent extracts of açai or blueberry were added to the other wells. $145 \mu \mathrm{L}$ of distilled water and $25 \mu \mathrm{L}$ of Folin-Ciocalteu reagent was then added to each well.

After incubation for $3 \mathrm{~min}$ at room temperature, $100 \mu \mathrm{L}$ of sodium carbonate was added and the plate was placed on a shaker for $25 \mathrm{~min}$ at room temperature. Absorbance was read at $650 \mathrm{~nm}$ using a GENios Pro $^{\mathrm{TM}}$ microplate reader with Magellan ${ }^{\mathrm{TM}}$ software. The total phenolic content was calculated using the calibration curve constructed with gallic acid as a standard and the result was expressed as gallic acid equivalent (GAE) $\mathrm{mg} / \mathrm{g}$ freeze-dried açai or blueberry (mean $\pm \mathrm{SD} ; \mathrm{n}=3$, triplicate analysis).

\subsection{Determination of the Total Flavonoid Content in Fruit Extracts}

The total flavonoid content was measured using the 
aluminium chloride assay [17]. In brief, $1 \mathrm{~mL}$ of a solvent extract of açai or blueberry or a catechin standard was added to $4 \mathrm{~mL}$ of distilled water in a $15-\mathrm{mL}$ tube. This preparation was mixed with $0.3 \mathrm{~mL}$ of sodium nitrite (5\%). After incubation for $5 \mathrm{~min}$ at room temperature, $0.3 \mathrm{~mL}$ of $10 \% \mathrm{AlCl}_{3}$ was added. After a further $6 \mathrm{~min}, 2 \mathrm{~mL}$ of $1 \mathrm{M}$ sodium hydroxide was added and the total volume was made with $10 \mathrm{~mL}$ with distilled water. The optical density was assessed at $510 \mathrm{~nm}$ using a microplate reader (TECAN). All samples were run in triplicate and compared with a blank The results were expressed as catechin equivalent (CHE) $\mathrm{mg} / \mathrm{g}$ freeze-dried Açai (mean $\pm \mathrm{SD}$; $\mathrm{n}=3$, triplicate analysis).

\subsection{Determination of the Antioxidant Activity of Fruit} Extracts Using the FRAP Assay

The antioxidant activity of the fruit extracts was determined using the FRAP assay, which is based on the ferric iron reducing power where the formation of a deep blue complex is readily discernible $\left(\mathrm{Fe}^{2+} / \mathrm{TPTZ}\right)$ [18]. In this assay, $10 \mu \mathrm{L}$ of serial dilutions of ascorbic acid standards $(0-1,000 \mu \mathrm{mol})$ or $10 \mu \mathrm{L}$ of samples were added to the wells of a 96-well plate, followed by $300 \mu \mathrm{L}$ of FRAP reagent. To prepare the reagent, $2.5 \mathrm{~mL}$ of $10 \mathrm{mmol} / \mathrm{L} \mathrm{TPTZ} \mathrm{in} 40 \mathrm{mmol} / \mathrm{L}$ $\mathrm{HCl}$ solution and $2.5 \mathrm{~mL}$ of $20 \mathrm{mmol} / \mathrm{L}$ ferric chloride hexahydrate solution was added to $25 \mathrm{~mL}$ of $0.3 \mathrm{M}$ acetate buffer ( $\mathrm{pH}$ 3.6; prepared fresh prior to the test). Absorbance was measured after 30 min incubation in the dark at $600 \mathrm{~nm}$ using a GENios reader at room temperature with Magellan ${ }^{\mathrm{TM}}$ software. The antioxidant capacity was calculated relative to the ascorbic acid serial dilution $(0-1,000 \mu \mathrm{M}$ Trolox equivalent) and expressed as $\mu \mathrm{M}$ ascorbic acid equivalent/L freeze-dried açai [19].

\subsection{Analysis of Phenolic Compounds by HPLC}

Açai polyphenols were extracted immediately prior to analysis from dried. A freeze-dried sample $(0.5 \mathrm{~g})$ was extracted 3 times in $5 \mathrm{~mL}$ of solvent [acidified methanol with $0.1 \%$ formic acid for anthocyanin compounds and other phenols]. The supernatants were collected, pooled and vortexed for $5 \mathrm{~min}$ and then centrifuged for $10 \mathrm{~min}$ at $1,500 \times \mathrm{g}$ at room temperature. Next, $50 \mu \mathrm{L}$ of the extract was filtered through a $0.45-\mu \mathrm{m}$ filter (Fisher Scientific, UK) [20]. HPLC was performed using an Agilent 1,100 series liquid chromatograph with a quaternary pump and a photodiode array detector (Hewlett-Packard Agilent, Bracknell, UK). A Nova Pak C18 4- $\mu$ m column (4.6 × $250 \mathrm{~mm}$ ) (Waters, Elstree, UK) was used to separate the phenolic constituents at a solvent flow rate of 0.4 $\mathrm{mL} / \mathrm{min}$ and the column was allowed to equilibrate for $15 \mathrm{~min}$ between each injection. Added $50 \mu \mathrm{L}$ of each sample or standard solution was injected for each analysis. The mobile phase A was 95\% HPLC water, $5 \%$ methanol and $0.1 \% \mathrm{HCl}$; mobile phase $\mathrm{B}$ was $50 \%$ HPLC water, $50 \%$ acetonitrile and $0.1 \% \mathrm{HCl}$. The identification of phenolic compounds from açai was based on the fragmentation patterns and retention times in the UV spectra compared with the standards. The detection wavelengths were 254, 280, 320 and $520 \mathrm{~nm}$. A standard curve was constructed to quantify the amount of each compound identified in açai extracts.

\subsection{Analysis of Carotenoids}

Carotenoids were identified by HPLC using available standards for $\beta$-carotene, all trans- retinal, retinal, $\beta$-cryptoxanthin, xanthophyll, lycopene (Sigma-Aldrich, UK) lutein and zeaxanthin (Extrasynthese, France) according to the method of Oliveira et al. [21]. In brief, $2 \mathrm{~g}$ of freeze-dried açai fruit (triplicate samples) was extracted in $10 \mathrm{~mL}$ methanol: tetrahydrofuran (60: 40, v/v) and then homogenized for $3 \mathrm{~min}$ using a vortex homogenizer. The sample was centrifuged for $5 \mathrm{~min}$ at $1,500 \mathrm{~g}$ and the supernatant collected. The pellet was extracted twice more or until the supernatant was colourless. The supernatants were transferred to a rotary evaporator at $30{ }^{\circ} \mathrm{C}$. The residues were reconstituted 
in $5 \mathrm{~mL}$ of methanol: hexane and the sample was passed through a $0.45-\mu \mathrm{m}$ filter, followed by injection of $100 \mu \mathrm{L}$ into HPLC vials. Individual carotenoids were separated using HPLC with an analytical LUNA C18 (2) ODS, (Phenomenex, detector, Torrance, CA, USA). The mobile phase was acetonitrile: tetrahydrofuran: methanol: $1 \%$ ammonium acetate in water (684: 220: 68: 28) and the sample was filtered using Millipore Type HA $0.45-\mu \mathrm{m}-$ and $47-\mu \mathrm{m}$-diameter membrane filters. The flow rate of the mobile phase was set to $3 \mathrm{~mL} / \mathrm{min}$ and the detection wavelength was $450 \mathrm{~nm}$ for carotenoids. Chromatography was performed at room temperature and the chromatograms were integrated using the DELTA chromatography data system (Data WorX Pty Ltd., Kangaroo Point, QLD Australia). Quantification was based on comparison with standard curves.

\subsection{Fatty Acid Analysis}

Freeze-dried açai samples ( $1 \mathrm{~g}$ ) were extracted in duplicate using diethyl ether and hexane (5: 4, v/v) and then evaporated to dryness at $60{ }^{\circ} \mathrm{C}$ for $1 \mathrm{~h}$ under nitrogen. The samples were dissolved in hexane methyl esters using sodium methoxide in methanol. Fatty acids were identified and quantified by gas chromatography using a Bruker 450-GC (Bruker Daltonik GmbH, Bremen, Germany) equipped with a CP-Sil 88 column $(100 \mathrm{~m} \times 0.25 \mathrm{~mm})$ coated with a $0.2-\mu \mathrm{m}$ film of cyanopropyl siloxane (CP-SIL 88, Varian Inc., Palo Alto, CA); $20 \mu \mathrm{L}$ of the sample was passed through a temperature gradient with hydrogen as the carrier gas $(30 \mathrm{psi} / 207 \mathrm{kPa})$. The column temperature was held at $70{ }^{\circ} \mathrm{C}$ for $4 \mathrm{~min}$, increased at a rate of $8^{\circ} \mathrm{C} / \mathrm{min}$ to $110^{\circ} \mathrm{C}$, then increased to $170{ }^{\circ} \mathrm{C}$ and held at $170{ }^{\circ} \mathrm{C}$ for $10 \mathrm{~min}$, increased to a final temperature of $240{ }^{\circ} \mathrm{C}$ at a rate of $3{ }^{\circ} \mathrm{C} / \mathrm{min}$ and held at $240{ }^{\circ} \mathrm{C}$ for $8 \mathrm{~min}$. The injector and detector temperatures were maintained at $255{ }^{\circ} \mathrm{C}$. Identification and quantification of fatty acids in açai extracts were based on comparisons with the retention times and standard curves of known spectra [22].

\subsection{Cell lines and Cell Culture}

The human HT-29 colorectal adenocarcinoma cell line was used in the cytotoxicity and anti-genotoxicity experiments. Cells were cultured in Dulbecco's modified Eagle's medium (Lonza, UK) supplemented with 10\% foetal bovine serum, $2 \mathrm{mM}$ L-glutamine and 100 $\mathrm{IU} / \mathrm{mL}$ penicillin/streptomycin (Lonza, UK). The cells were passaged 21-35 times with 2 passages per week in T75 cell culture flasks (Fisher Scientific, UK) [23].

\subsection{Cytotoxicity}

HT-29 cells were seeded in a 96-well plate at a concentration of $1.6 \times 10^{5}(250 \mu \mathrm{L})$ cells $/ \mathrm{mL}$ and incubated for $24 \mathrm{~h}$ at $37{ }^{\circ} \mathrm{C}$ prior to the assay. Dilutions of açai or blueberry extracts $[0 \%, 1 \%, 2.5 \%$, $5 \%$ and $10 \%(\mathrm{v} / \mathrm{v})$ in medium] were prepared in carrier control and used to treat the cells, followed by incubation for $24 \mathrm{~h}$ at $37^{\circ} \mathrm{C}$. Thereafter, the medium was removed and $100 \mu \mathrm{L}$ of DAPI $(3 \mathrm{mM})$ was added for $4 \mathrm{~h}$ at $37^{\circ} \mathrm{C}$. Subsequently, DAPI was removed and absorbance was measured at $540 \mathrm{~nm}$ using a microplate reader (TECAN). The experiment was performed in triplicate in independent experiments. The results were expressed as the mean percentage cell survival, which was normalized against the control (without treatment).

\subsection{Genotoxicity (Comet Assay)}

The method used was based on that reported by Brown [24]. In brief, HT-29 cells were grown for 3 days and treated with açai or blueberry extracts for 30 min at $37^{\circ} \mathrm{C}$ before harvesting. The cell concentration was adjusted to $3.2 \times 10^{6}$ cells $/ \mathrm{mL}(450 \mu \mathrm{L})$ to study exogenously induced DNA damage, where cells were treated with $75 \mu \mathrm{mol} \mathrm{H}_{2} \mathrm{O}_{2}(100 \mu \mathrm{L})$ (Sigma-Aldrich, UK) and incubated on ice $\left(4^{\circ} \mathrm{C}\right)$ for $5 \mathrm{~min}$. PBS was used as the negative control and $\mathrm{H}_{2} \mathrm{O}_{2}$-treated cells not exposed to the sample extracts were included as the positive control. Cell suspensions were centrifuged for $5 \mathrm{~min}$ at $250 \mathrm{~g}$ and $4{ }^{\circ} \mathrm{C}$ and the supernatants were discarded. The cells were resuspended in $85 \mu \mathrm{L}$ of $0.85 \%$ 
low-melting- point agarose (Sigma-Aldrich, UK). The suspension was mixed well and aliquots were dispensed onto frosted slides (1\% normal agarose gel with $150 \mu \mathrm{L}$ of PBS on each slide and large cover slips) (Sigma-Aldrich, UK). These slides were incubated in the fridge for $10 \mathrm{~min}$ before lysis buffer [pH 10; 1\% Triton X-100 (2.5 NaCl, 0.1 M EDTA, $0.01 \mathrm{M}$ Tris); Sigma-Aldrich, UK] for $1 \mathrm{~h}$ at $4{ }^{\circ} \mathrm{C}$. The slides were washed with $100 \mathrm{~mL}$ of enzyme buffer $(\mathrm{pH}$ 8.0; $400 \mathrm{mM}$ HEPES, $1 \mathrm{M} \mathrm{KCl,} 5 \mathrm{mM}$ EDTA, 2 $\mathrm{mg} / \mathrm{mL}$ BSA; Sigma-Aldrich, UK) in a staining jar 3 times for $5 \mathrm{~min}$ at $4{ }^{\circ} \mathrm{C}$ and compared with the controls. To assess the oxidative damage, endonuclease III (Endo III) or formamidopyrimidine-DNA glycosylase (FPG) (100 $\mu \mathrm{L}$ ) was applied to a subset of slides post-treatment, whereas the control slides were exposed to enzyme reaction buffer in the absence of enzymes. The slides were incubated at $37{ }^{\circ} \mathrm{C}$ for 45 min with Endo III or 30 min with FPG. DNA was allowed to unwind in electrophoresis buffer (10 M NaOH, 0.2 M EDTA, pH 13.5; Sigma-Aldrich, UK) at $4{ }^{\circ} \mathrm{C}$ for $20 \mathrm{~min}$ before electrophoresis $(20 \mathrm{~min}$ at $26 \mathrm{~V}, 300 \mathrm{~mA}, 0.037$ $\mathrm{V} / \mathrm{cm})$. The slides were then washed 3 times with neutralizing buffer $(0.4 \mathrm{M}$ Tris, $\mathrm{pH} 7.5$ with $\mathrm{HCl}$; Sigma-Aldrich, UK) at $4{ }^{\circ} \mathrm{C}$ for $5 \mathrm{~min}$. All slides were stained with $45 \mu \mathrm{L}$ of ethidium bromide $(20 \mu \mathrm{g} / \mathrm{mL}$ in PBS) and stored in a dark moist box at $4{ }^{\circ} \mathrm{C}$ for $\leq 48 \mathrm{~h}$.

Comets were visualized at $400 \times$ magnification using an epifluorescence microscope (Olympus, Bx51). 50 cells per sample were counted and percentage tail were quantified using Komet 5.5 image analysis software (Kinetic Imaging Ltd., Liverpool,
UK). Mean values were calculated for 50 cells from each slide (each sample in triplicate) and the data were expressed as the mean percentage tail DNA compared with the controls [23].

\subsection{Statistical Analysis}

All experiments were analysed using PASW statistics 18 (SPSS) software. Independent samples $t$-tests were used to assess significant differences in the total polyphenol, flavonoid contents and antioxidant activity (FRAP) of the 2 samples (açai and blueberry). One-way ANOVA with Dunnett's post-hoc test was used to analyse the comet assay data. The data were expressed as the mean of 3 individual analyses for each sample (mean $\pm \mathrm{SD} ; \mathrm{n}=3$ ).

\section{Results}

\subsection{Phytochemical Composition of Fruit Extracts}

The Folin-Ciocalteu method was used to determine the total phenolic content in the 2 different fruits. As expected, the total phenolic content was very high in both fruits (Açai 105.1 GAE mg/g and blueberry 182.6 GAE $\mathrm{mg} / \mathrm{g}$ ) although the dried blueberry extract had a higher phenolic content compared with the açai pulp extract $(P<0.001)$. In contrast, the aluminium chloride assay Table 7 showed that the freeze-dried açai pulp extract contained significantly higher levels of flavonoids compared with blueberry (Açai 54.27 CHE mg/g and blueberry $32.04 \mathrm{CHE} \mathrm{mg/g})(P<$ 0.001). This may explain the comparable antioxidant capacities of both fruits observed in the FRAP assay (Açai $1,048.76 \mu \mathrm{M} / \mathrm{L}$ ascorbic acid and blueberry $1,033.11 \mu \mathrm{M} / \mathrm{L}$ ascorbic acid).

Table 1 Total polyphenol and flavonoid contents and antioxidant capacity (FRAP assay) freeze-dried fruit extracts.

\begin{tabular}{llll}
\hline Samples & $\begin{array}{l}\text { Total Phenolic content } \\
(\mathrm{GAE} \mathrm{mg} / \mathrm{g})\end{array}$ & $\begin{array}{l}\text { Total flavonoid content } \\
(\mathrm{CHE} \mathrm{m} / \mathrm{g})\end{array}$ & $\begin{array}{l}\text { Antioxidant activity } \\
\text { (Ascorbic acid } \mu \mathrm{M} / \mathrm{L})\end{array}$ \\
\hline Açai & $105.1 \pm 2.4$ & $54.27 \pm 0.28$ & $1,048.76 \pm 57.25$ \\
Blueberry & $182.6 \pm 10.2$ & $32.04 \pm 2.30$ & $1,033.11 \pm 37.73$ \\
P value for comparison & 0.001 & 0.001 & 0.073 \\
\hline
\end{tabular}

*The data presented for the total phenolics are the mean values \pm SD of 4 replicates $(\mathrm{n}=4)$ expressed as $\mathrm{mg} / \mathrm{g}$ of gallic acid equivalent (GAE) per $\mathrm{g}$. The total flavonoid content is the mean value of 3 replicates $(n=3) \pm$ SD expressed as catechin equivalents $\mathrm{mg} / \mathrm{g}$. The total antioxidant activity is the mean values from the FRAP assay $(\mathrm{n}=3) \pm \mathrm{SD}$ and expressed as $\mu$ mol/L of ascorbic acid. $P$-value are from $t$-test comparisons of açai and blueberry extracts. 
Table 2 Identification and quantification of phenolic compounds in açai fruit extracts by HPLC.

\begin{tabular}{ll}
\hline Compound & Açai extract \\
\hline Gallic acid & $701.60 \pm 4.48$ \\
3,4-Dihydroxybenzoic acid & $5.03 \pm 0.56$ \\
4-Hydroxybenzoic acid & $3.37 \pm 0.36$ \\
2,5-Dihydroxybenzoic acid & $28.18 \pm 0.80$ \\
Chlorogenic acid & $37.65 \pm 1.55$ \\
Caffeic acid & $8.12 \pm 0.32$ \\
Syringic acid & $11.23 \pm 0.09$ \\
Ferulic acid & $2.46 \pm 0.24$ \\
Trans-cinnamic acid & $1.65 \pm 0.02$ \\
Quercetin & $39.02 \pm 0.58$ \\
Vanillic acid & $1.02 \pm 0.24$ \\
Cyanidin-3-O-glucoside & $998.74 \pm 7.47$ \\
Cyanidin-3-O-rutinoside & $433.98 \pm 11.61$ \\
Pelargonidin-3-O-glucoside & $17.58 \pm 0.35$ \\
Peonidin-3-O-rutinoside & $544.50 \pm 77.60$ \\
\hline
\end{tabular}

Table 3 Fatty acids present in açai pulp extracts (mg/g Dry weight total fatty acids).

\begin{tabular}{ll}
\hline Compounds Identified & Açai extracts \\
\hline Palmitic acid & 134.1 \\
Oleic acid & 321.5 \\
Linoleic acid & 65.9 \\
Total fatty acids & 521.5 \\
\hline
\end{tabular}

\subsection{Polyphenol Profile}

Table 8 provides a summary of the phytochemicals identified in açai pulp extracts. The major polyphenols in the açai extract were phenolic acids (gallic acid, 3,4-dihydroxybenzoic acid, 4-hydroxybenzoic acid, 2,5-dihydroxybenzoic acid, syringic acid and vanillic acid), flavonols (quercetin), hydroxycinnamic acids (chlorogenic acid, caffeic acid and ferulic acid) and anthocyanins, including cyanidin-3-O-glucoside (998.7 mg/100 $\mathrm{g}$ DW), cyanidin-3-O-rutinoside $\quad(434.0 \quad \mathrm{mg} / 100 \quad \mathrm{~g})$, pelargonidin-3-O-glucoside $(17.6 \mathrm{mg} / 100 \mathrm{~g})$ and peonidin-3-O-rutinoside $(544.5 \mathrm{mg} / 100 \mathrm{~g}$ ) Figure 18.

\subsection{Carotenoid Profile}

Figure 19 summarizes the carotenoids identified in the freeze-dried açai pulp extract. The major carotenoids identified were lutein $(43.9 \mathrm{mg} / 100 \mathrm{~g})$ and $\beta$-carotene $(439.1 \mathrm{mg} / 100 \mathrm{~g})$. Standards were included for other carotenoids (trans-retinal, retinal, $\beta$-cryptoxanthin, xanthophyll, lycopene and zeaxanthin). However, these compounds were not detected in the freeze-dried açai pulp extract.

\subsection{Fatty Acid Profile}

Gas chromatography was used to elucidate the fatty acid composition of açai pulp extracts. The total fatty acid content was $521.5 \mathrm{mg} / \mathrm{g}$ DW and 3 principal fatty acids were identified. Oleic acid comprised $61.6 \%$ of the total fatty acids $(321.5 \mathrm{mg} / \mathrm{g} \mathrm{DW})$, followed by palmitic acid $(25.7 \% ; 134.1 \mathrm{mg} / \mathrm{g}$ DW) and linoleic acid (12.6\%; $65.9 \mathrm{mg} / \mathrm{g}$ DW) Table 9. These data are consistent with the results of the only other previous study to report on the fatty acid content in açai pulp [5].

\subsection{Cytotoxicity of Açai Berry in HT-29 Cells}

No appreciable cytotoxicity was observed when açai or blueberry extracts were applied to HT-29 cells at concentrations of $0 \%, 1 \%, 2.5 \%$ and $5 \%$ (data not shown). Thus, an extract concentration of $2.5 \%$ [2.5 $\mathrm{mg} / \mathrm{mL}$ in medium $(\mathrm{v} / \mathrm{v})$ ] was considered suitable for the genotoxicity experiments. 


\subsection{Comet Assay}

HT-29 cells were pre-treated with $2.5 \%(\mathrm{v} / \mathrm{v})$ açai or blueberry extracts for $30 \mathrm{~min}$ prior to the induction of oxidative DNA damage with $\mathrm{H}_{2} \mathrm{O}_{2}$ Figure $21 \mathrm{~A}$, or they were treated with açai or blueberry extracts without peroxide challenge to assess the effects of the extracts on endogenous DNA damage. Following treatment with peroxide DNA strand breaks were observed to increase in the HT29 cells, from background levels of under $6 \%$ tail DNA rising to closer to $11 \%$ Figure 20 (Contro $11 \%$, açai $6.6 \%$ and blueberry $9.3 \%$ ). In addition to strand breaks, the Endo III and FPG modified assays demonstrate increased levels of both oxidised purine and pyrimidine bases. Pre-incubation with extracts of açai, but not blueberry, protected against peroxide-induced DNA strand breaks. And results from the modified comet assays showed protection against peroxide induced oxidation of both pyrimidines and purines Endo III (Control 12.6\%, Açai 8\% and blueberry $11.6 \%$ ) FPG (Control $14 \%$, açai $7.3 \%$ and blueberry $10.3 \%$ ). In the absence of peroxide neither the extract of açai or the extract of blueberry was shown to induce DNA strand breaks or oxidative damage and

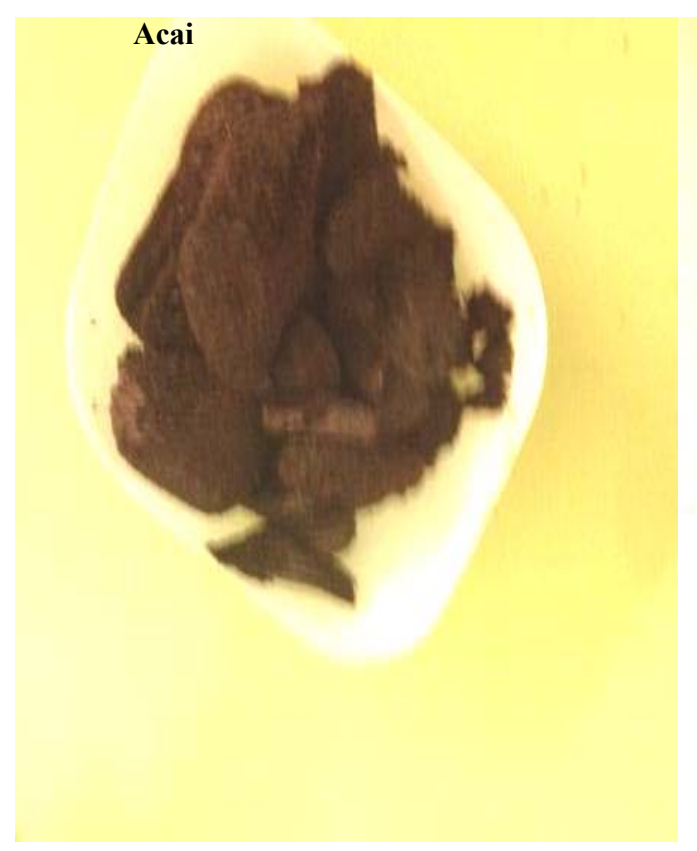

Fig. 1 Samples after freeze -dried; Açai pulp and Blueberries. neither extract conferred protection against the endogenous DNA damage Figure 21B.

\section{Discussion}

It is hypothesized that non-nutritive plant polyphenols and carotenoids contribute, in part, to the reduced risk of chronic disease associated with consuming a diet rich in fruits and vegetables [25]. One putative beneficial mode of action for plant polyphenols in the body is their antioxidant effect. In this study, we determined the phytochemical profile of açai fruit pulp and we showed that it is a very rich source of flavonoids. The relative abundance of secondary metabolites in most fruits varies according to the ripening and harvest time and growing conditions [26]. A drawback to this study is the limited regional and seasonal variety of açai samples studied, that said, our polyphenol data are consistent with the results of previous studies [13, 27]. In the present work, we identified phenolic acids (gallic acid, 3,4-dihydroxybenzoic acid, 4-hydroxybenzoic acid, gentisic acid, syringic acid and vanillic acid), flavonols (quercetin), hydroxycinnamic acids (chlorogenic acid, caffeic acid and ferulic acid) and an abundance of anthocyanins in açai extracts Figure .

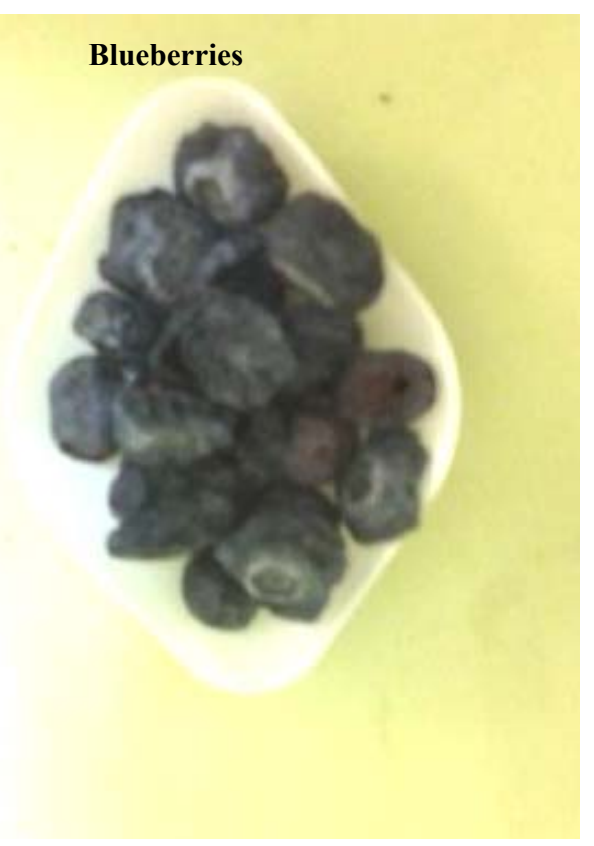



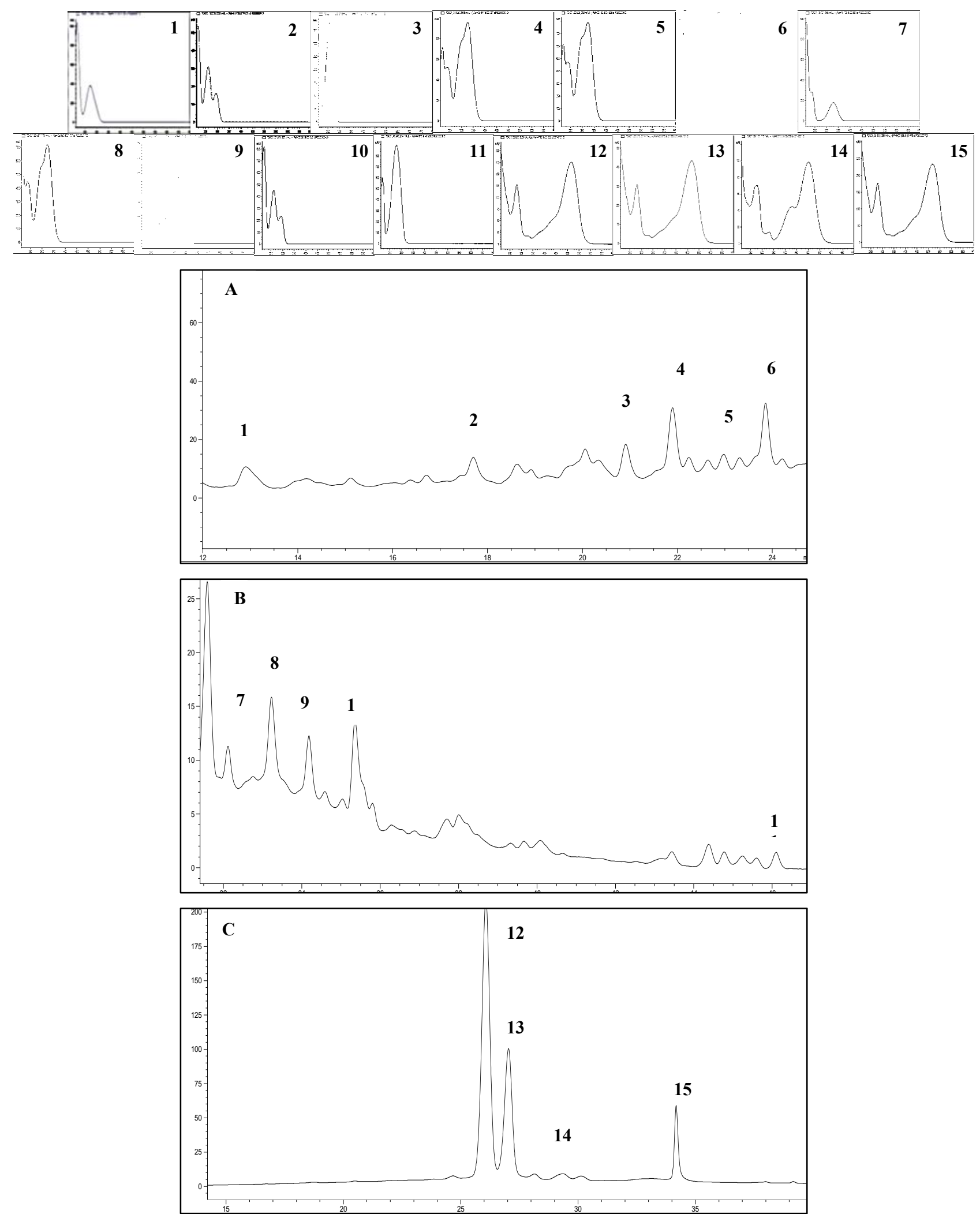

Fig. 2 Chromatograms obtained by HPLC using freeze-dried acai pulp. Polyphenol compounds detected (A) at $280 \mathrm{~nm}: 1$, gallic acid; 2, dihydroxybenzonic acid; 3, 4-hydroxybenzonic acid; 4, chlorogenic acid; 5, caffeic acid; 6, syringic acid; (B) at $254 \mathrm{~nm}$ : 7, 2,5-dihydroxybenzoic acai; 8, ferulic acid; 9, quercetin; 10, vanillic acid; 11, trans-cinnamic acid and (C) at 520 nm: 12, cyanidin-3-O-glucoside; 13, cyanidin-3-O- rutinoside; 14, pelargonidin-3-O-glucoside; 15, peonidin-3-O-rutinoside. 


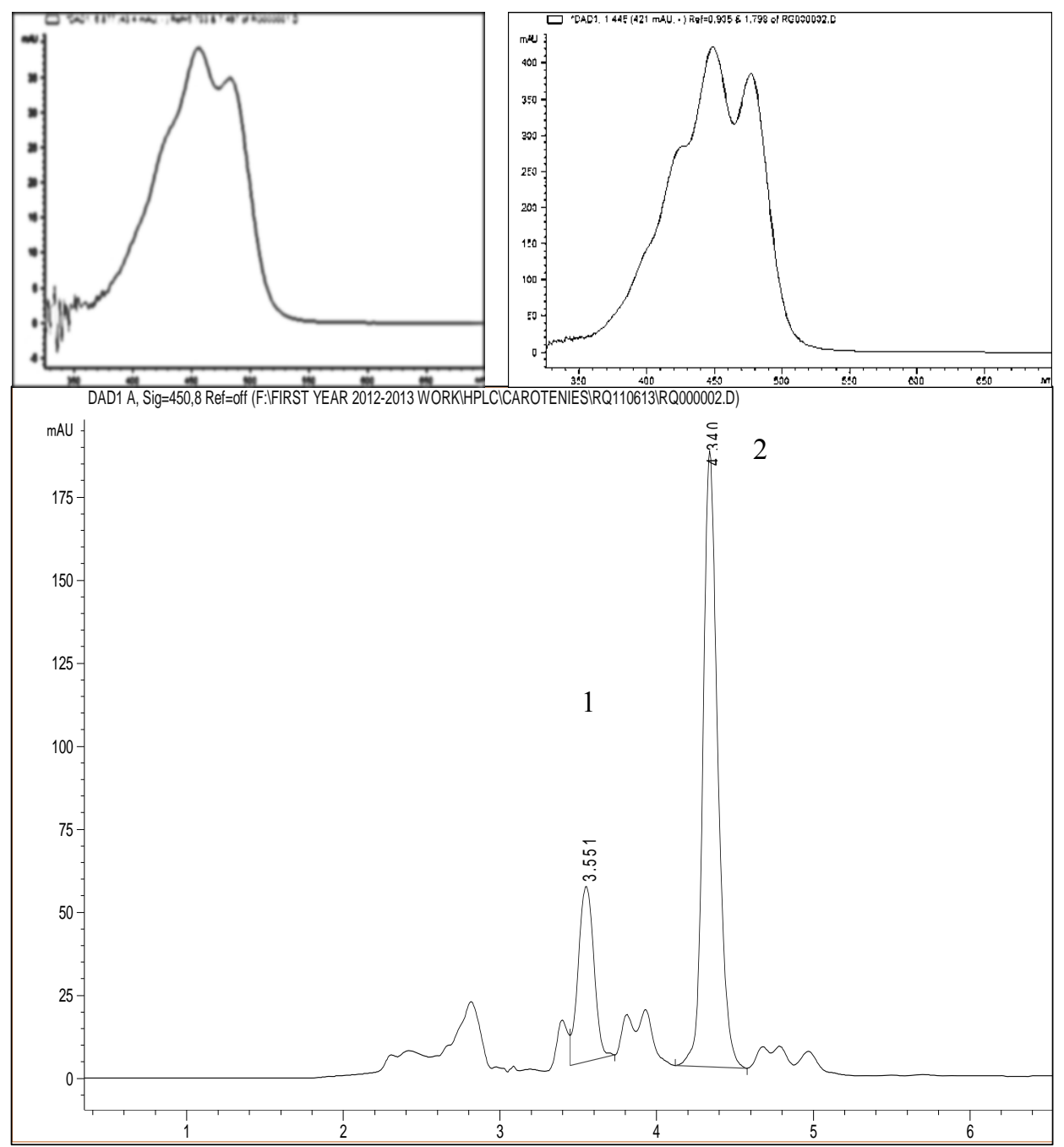

Fig. 3 HPLC spectra of the freeze-dried açai pulp extract to detect carotenoid compounds at $450 \mathrm{~nm}: \mathbf{1}, \beta$-carotene and 2 , lutein.
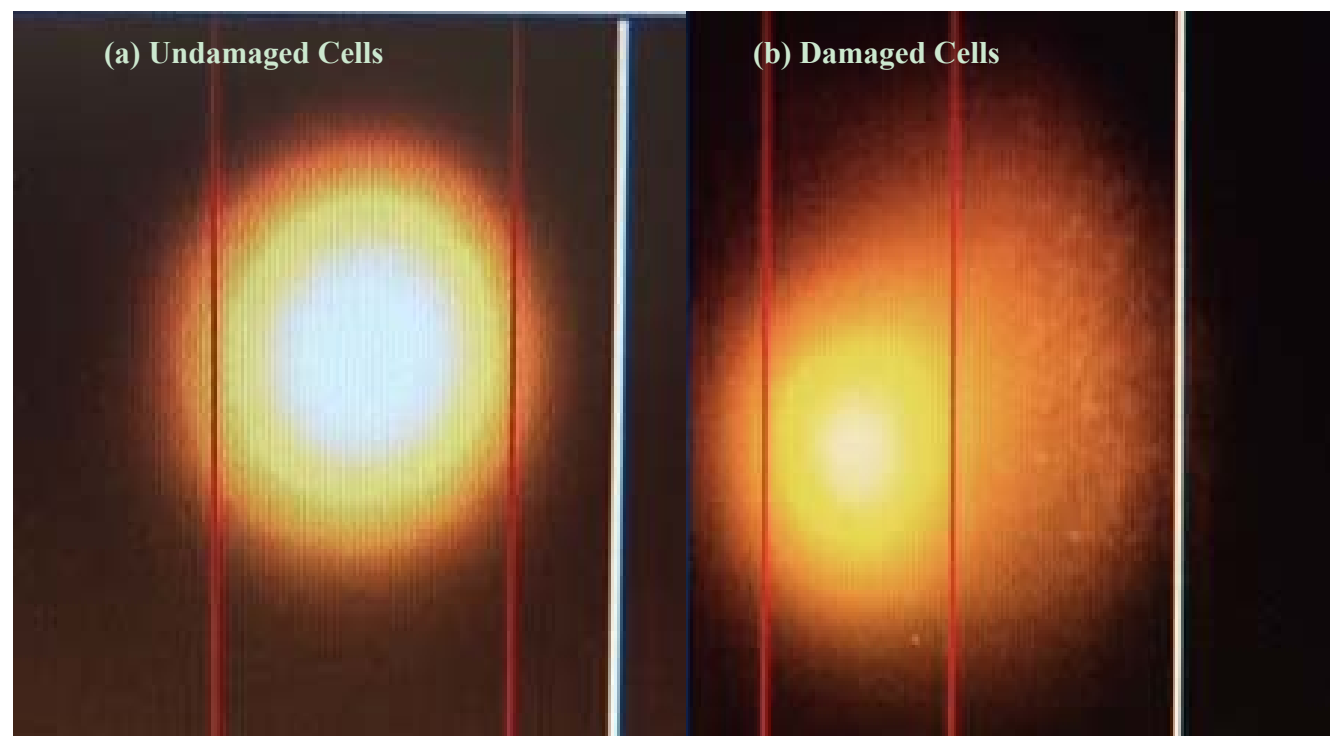

Fig. 4 Comet assay images. 

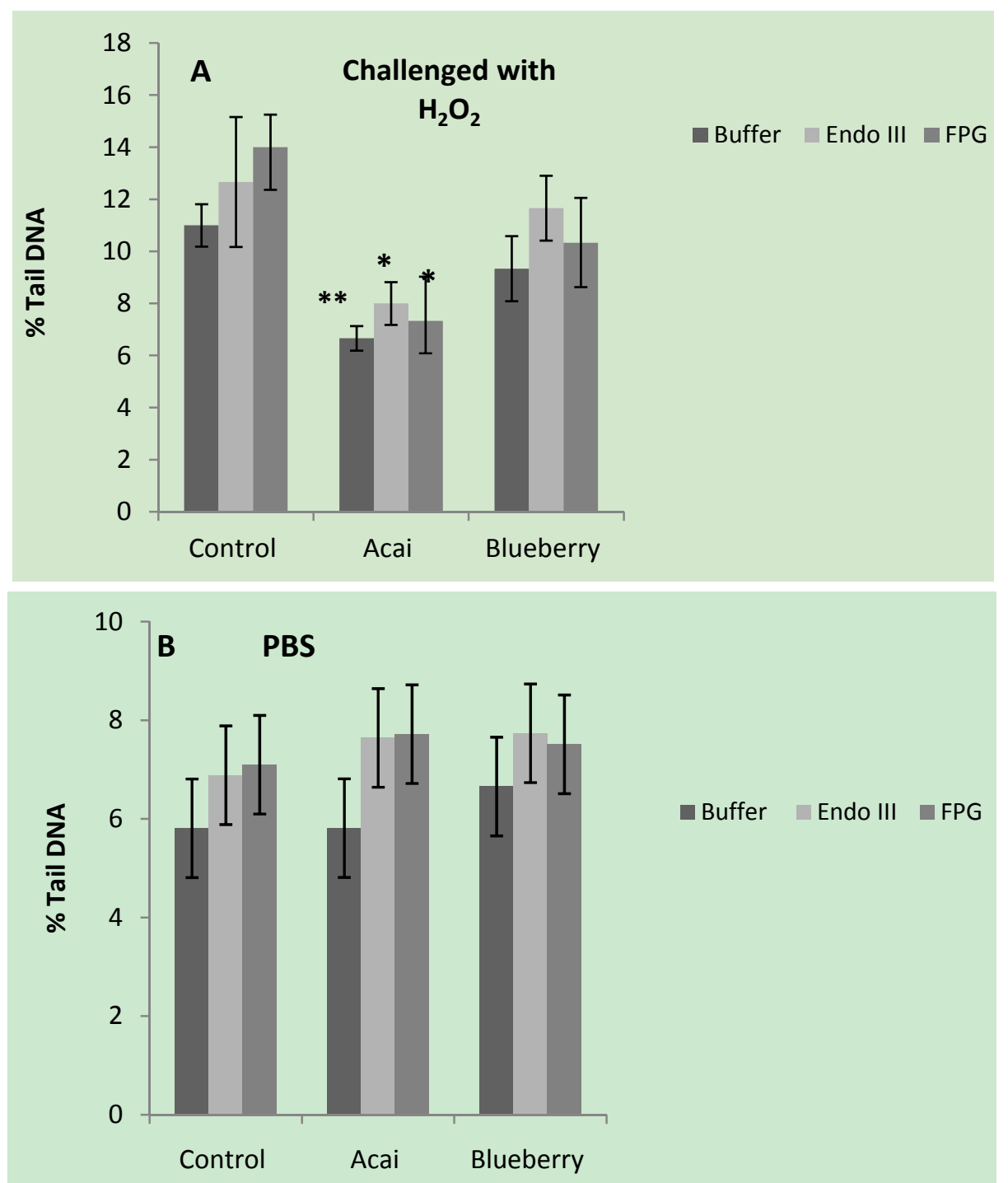

Fig. 5 Anti-genotoxic effects of fruit extracts on HT-29 cells (comet assay). HT-29 cells were treated with extracts (2.5 $\mathrm{mg} / \mathrm{mL}$ in $\mathrm{MeOH}$ ) for $30 \mathrm{~min}$ before the experiment. (A) The effect of the extracts on tail DNA when cells were challenged with $\mathrm{H}_{2} \mathrm{O}_{2}$ (75 $\mu \mathrm{M}$ for $5 \mathrm{~min}$ ), representing an exogenous source of free radical damage. (B) Cells were challenged with PBS, demonstrating the effects of the fruit extracts on endogenous oxidative DNA damage. Buffer represents global DNA damage. Endo III enzyme was used to assess oxidized pyrimidines. FPG enzyme was used to assess oxidized purines. The data represent the mean of 3 experiments \pm SD. One-way ANOVA and Dunnett's test: $* P<0.01, * * P<0.001$, significant differences compared with the control.

Furthermore, we showed that the extracts of açai have an in vitro antioxidant capacity similar to that of blueberry extracts, this capacity may be a function of both the phenolics and the carotenoids identified. Previous reports have established powerful anti-oxidant effects for açai, however here we go a step further, demonstrating that açai extracts protect against oxidative DNA damage in a biological system to a greater extent than extracts of blueberry. This finding may be much more relevant to human health than purely chemical measures of antioxidant function as cellular oxidative stress is implicated in the development of cardiovascular disease and cancer [28].

In this study, we have identified the fat composition in açai pulp and we found that açai has content high amount of fatty acids contains mainly oleic acid (MUFA) and linoleic acid (PUFA). The lipid fraction of 
açai is similar to that of olive oil, which contain mainly of oleic acid found in animals and vegetables oils and is the major component of the mediterranean diet that high in fruit and vegetable which is responsible for health benefits such as breast cancer and other chronic diseases $[29,30]$. Also with high antioxidant capacity of Acai pulp, which may be associated with the production, lipid fraction from oxidation in the plant and fruit. The effects of dietary antioxidants in the human body are unclear and phytochemicals with powerful antioxidant effects as assessed by purely chemical measures may not necessarily retain these properties in living systems [31]. Inferences based on in vitro data assume that antioxidants survive the digestive environment of the gastrointestinal tract and that the compounds are taken up into the bloodstream or at least into the cells lining the gastrointestinal tract where they may act. Returning to the polyphenol profile of açai, in vitro studies suggest that anthocyanins, cyanidin-3-O-glucoside and cyanidin-3-O-rutinoside are associated with the inhibition of amylase activity [32], anti-mutagenic effects [33], suppression of proliferation and induction of apoptosis [34], protection against LDL oxidation [35] and protection against endothelial dysfunction [36]. Similarly, high antioxidant and anti-mutagenic capacities have been reported for peonidin-O-rutinoside [37], which also inhibits the growth of cultured cancer cells [34]. The hydroxycinnamate, caffeic acid has previously been shown to exert a variety of anti-inflammatory and anti-cancer effects in vitro [38] and has also been shown to help control blood glucose and vascular dysfunction in rats [39]. The carotenoid lutein may protect against oxidative stress [40], although evidence of protection against cardiovascular disease is equivocal [41]. The combined effects of these phytochemicals within the body, as part of a consumed food, also assumes their bioavailability, and the more general benefits claimed for açai appear to have been inferred on the basis of established health benefits associated with consuming other polyphenol-rich berry foods in areas such as cardiovascular and metabolic disease risk [42].

Here we report a similar polyphenol content in açai relative to blueberry, but we would caution against making inferences on the basis of phenolic equivalents. Interventions with very high doses of antioxidants have not always equated to protection against disease and in some cases these interventions have been harmful [43]. Many of the noted benefits of polyphenols are often not associated with a classic linear dose-response relationship during in vitro studies [42] and some phenolics may actually act as pro- oxidants at high concentrations. Thus, it is important to independently characterize the health benefits of consuming açai as a food, very few studies have addressed this. Anti- mutagenic effects have been reported on the basis of in vivo models [44], as well as anti-hypercholesterolemic effects [45]. We only identified 4 small dietary intervention studies in human volunteers. The highest quality study was a 4-way crossover trial with açai pulp and juice where apple sauce and a polyphenol-free beverage were used as controls. This study established the bioavailability of açai polyphenols on the basis of urinary recovery and also demonstrated an increase in the post-consumption plasma antioxidant capacity in 12 volunteers [10]. Similarly, Jensen et al. observed an increase in serum antioxidant levels and a reduction in lipid peroxidation following acute consumption of a 'polyphenol-enriched' açai-based beverage in a double-blind crossover [46]. More recently, the same authors reported slight improvements in the range of motion in arthritic patients following chronic consumption of the same product in a small non-controlled chronic study [47]. Udani et al. observed significant reductions in plasma glucose, insulin and total cholesterol levels in a small non-controlled pilot study based on the chronic consumption of açai pulp in overweight volunteers [48]. Each of these studies demonstrates the bioavailability of polyphenols and suggested in vivo 
antioxidant effects. However, only two of the studies used pure açai pulps and only one of these followed a blinded controlled design and in this study the principal outcome measure (plasma antioxidant status) would not satisfy the EFSA criteria for a health claim on food.

Our study is limited in that, it is in vitro work and uses experimental exposure levels of açai phytochemicals that may not be achievable through diet, the results are however comparable with the effects of blueberry in these assays. Furthermore, the findings here support those of others and are suggestive of potential health benefits for açai, more research is needed to establish the digestive fate of açai polyphenols, to determine their actual effects on the human body, and to determine the levels of exposure required to confer any benefits to health.

\section{Acknowledgments}

We thank the Saudi Arabian Ministry of Education for funding this study. We also thank Dr. Kirsty Kliem and Paulina Erceg for helping us in this study.

\section{References}

[1] Ribeiro, J. C., Antunes, L. M. G., Aissa, A. F., Darin, J., De Rosso, V. V., Mercadante, A. Z., and Bianchi, Md. L. P. 2010. "Evaluation of the genotoxic and antigenotoxic effects after acute and subacute treatments with açai pulp ( $<\mathrm{i}>$ Euterpe oleracea $</ \mathrm{i}>$ Mart.) on mice using the erythrocytes micronucleus test and the comet assay." Mutation Research/Genetic Toxicology and Environmental Mutagenesis 695 (1): 22-8.

[2] Heinrich, M., Dhanji, T., and Casselman, I. 2011. "Açai (Euterpe oleracea Mart.)-A phytochemical and pharmacological assessment of the species' health claims." Phytochemistry Letters 4 (1): 10-21. doi: 10.1016/j.phytol.2010.11.005.

[3] Lichtenthäler, R., Rodrigues, R. B., Maia, J. G. S., Papagiannopoulos, M., Fabricius, H., and Marx, F. 2005. "Total oxidant scavenging capacities of Euterpe oleracea Mart.(Acai) fruits." International Journal of Food Sciences and Nutrition 56 (1): 53-64.

[4] Kang, J., Thakali, K. M., Xie, C., Kondo, M., Tong, Y., Ou, B., Jensen, G., Medina, M. B., Schauss, A. G., and Wu, X. 2012. "Bioactivities of açaí (Euterpe precatoria Mart.) fruit pulp, superior antioxidant and anti-inflammatory properties to Euterpe oleracea Mart." Food Chemistry 133 (3): 671-7. doi: 10.1016/j.foodchem.2012.01.048.

[5] Schauss, A. G., Wu, X., Prior, R. L., Ou, B., Huang, D., Owens, J., Agarwal, A., Jensen, G. S., Hart, A. N., and Shanbrom, E. 2006. Antioxidant capacity and other bioactivities of the freeze-dried Amazonian palm berry, Euterpe oleraceae mart. (acai).

[6] Singh, R., DeMeester, F., Pella, D., Basu, T. K., and Watson, R. R. 2009. "Globalization of Dietary Wild Foods Protect against Cardiovascular Disease and all Cause Mortalities? A Scientific Satement from the International College of Cardiology, Columbus Paradigm Institute and the International College of Nutrition." Open Nutraceuticals Journal 2.

[7] Ness, A. R., and Powles, J. W. 1997. "Fruit and vegetables, and cardiovascular disease: a review." International Journal of Epidemiology 26 (1): 1-13.

[8] Sabbe, S., Verbeke, W., Deliza, R., Matta, V., and Van Damme, P. 2009. "Effect of a health claim and personal characteristics on consumer acceptance of fruit juices with different concentrations of açaí $(<\mathrm{i}>$ Euterpe oleracea $<$ i $>$ Mart.)." Appetite 53 (1): 84-92.

[9] Borges, G., Degeneve, A., Mullen, W., and Crozier, A. 2009. "Identification of Flavonoid and Phenolic Antioxidants in Black Currants, Blueberries, Raspberries, Red Currants, and Cranberries $\uparrow$.” Journal of Agricultural and Food Chemistry 58 (7): 3901-9.

[10] Mertens-Talcott, S. U., Rios, J., Jilma-Stohlawetz, P., Pacheco-Palencia, L. A., Meibohm, B., Talcott, S. T., and Derendorf, H. 2008. "Pharmacokinetics of anthocyanins and antioxidant effects after the consumption of anthocyanin-rich acai juice and pulp (Euterpe oleracea Mart.) in human healthy volunteers." Journal of Agricultural and Food Chemistry 56 (17): 7796-802.

[11] Seeram, N. P., Adams, L. S., Zhang, Y., Lee, R., Sand, D., Scheuller, H. S., and Heber, D. 2006. "Blackberry, black raspberry, blueberry, cranberry, red raspberry, and strawberry extracts inhibit growth and stimulate apoptosis of human cancer cells in vitro." Journal of Agricultural and Food Chemistry 54 (25): 9329-39.

[12] Rodriguez-Mateos, A., Rendeiro, C., Bergillos-Meca, T., Tabatabaee, S., George, T. W., Heiss, C., and Spencer, J. P. 2013. "Intake and time dependence of blueberry flavonoid-induced improvements in vascular function: a randomized, controlled, double-blind, crossover intervention study with mechanistic insights into biological activity." The American Journal of Clinical Nutrition 98 (5): 1179-91.

[13] Pacheco-Palencia, L. A., Mertens-Talcott, S., and Talcott, S. T. 2008. "Chemical composition, antioxidant properties, and thermal stability of a phytochemical 
enriched oil from Acai (Euterpe oleracea Mart.).” Journal of Agricultural and Food Chemistry 56 (12): 4631-6.

[14] Anwar, F., Abdul, Qayyum, H. M., Ijaz, Hussain, A., and Iqbal, S. 2010. "Antioxidant activity of $100 \%$ and $80 \%$ methanol extracts from barley seeds (Hordeum vulgare L.): stabilization of sunflower oil." Grasas y Aceites 61 (3): 237-43.

[15] Choi, Y., Jeong, H.-S., and Lee, J. 2007. "Antioxidant activity of methanolic extracts from some grains consumed in Korea." Food Chemistry 103 (1): 130-8.

[16] Sun, J., Chu, Y.-F., Wu, X., and Liu, R. H. 2002. "Antioxidant and antiproliferative activities of common fruits." Journal of Agricultural and Food Chemistry 50 (25): 7449-54.

[17] Marinova, D., Ribarova, F., and Atanassova, M. 2005. "Total phenolics and total flavonoids in Bulgarian fruits and vegetables." Journal of the University of Chemical Technology and Metallurgy 40 (3): 255-60.

[18] Benzie, I. F., and Strain, J. 1996. "The ferric reducing ability of plasma (FRAP) as a measure of 'antioxidant power': the FRAP assay." Analytical Biochemistry 239 (1): $70-6$.

[19] Thaipong, K., Boonprakob, U., Crosby, K., Cisneros-Zevallos, L., and Byrne, D. H. 2006. "Comparison of ABTS, DPPH, FRAP, and ORAC assays for estimating antioxidant activity from guava fruit extracts." Journal of Food Composition and Analysis 19 (6): 669-75.

[20] Rodriguez-Mateos, A., Cifuentes-Gomez, T., Tabatabaee, S., Lecras, C., and Spencer, J. P. 2012. "Procyanidin, anthocyanin, and chlorogenic acid contents of highbush and lowbush blueberries." Journal of Agricultural and Food Chemistry 60 (23): 5772-8.

[21] Oliveira, C., Silva Ferreira, A., Mendes Pinto, M., Hogg, T., Alves, F., and Guedes de Pinho, P. 2003. "Carotenoid compounds in grapes and their relationship to plant water status." Journal of Agricultural and Food Chemistry 51 (20): 5967-71.

[22] Kliem, K. E., Shingfield, K. J., Livingstone, K. M., and Ian Givens, D. 2013. Seasonal variation in the fatty acid composition of milk available at retail in the United Kingdom and implications for dietary intake. Food chemistry.

[23] Coates, E. M., Popa, G., Gill, C. I., McCann, M. J., McDougall, G. J., Stewart, D., and Rowland, I. 2007. "Colon-available raspberry polyphenols exhibit anti-cancer effects on in vitro models of colon cancer." $J$. Carcinog 6: 4. doi: 10.1186/1477-3163-6-4.

[24] Brown, E. M., McDougall, G. J., Stewart, D., Pereira-Caro, G., Gonzalez-Barrio, R., Allsopp, P., Magee, P., Crozier, A., Rowland, I., and Gill, C. I. 2012. "Persistence of anticancer activity in berry extracts after simulated gastrointestinal digestion and colonic fermentation." PLoS One 7 (11): e49740. doi: 10.1371/journal.pone.0049740.

[25] Nielsen, I. L. F., Dragsted, L. O., Ravn-Haren, G., Freese, R., and Rasmussen, S. E. 2003. "Absorption and excretion of black currant anthocyanins in humans and watanabe heritable hyperlipidemic rabbits." Journal of Agricultural and Food Chemistry 51 (9): 2813-20.

[26] Dai, J., and Mumper, R. J. 2010. "Plant phenolics: extraction, analysis and their antioxidant and anticancer properties." Molecules 15 (10): 7313-52. doi: 10.3390/molecules15107313.

[27] Schauss, A. G., Wu, X., Ronald, L., Ou, B., Patel, D., Huang, D., and Kababick, J. P. 2006. "Phytochemical and nutrient composition of the freeze-dried Amazonian palm berry, Euterpe oleraceae Mart. (Acai)." Journal of Agricultural and Food Chemistry 54 (22): 8598-603.

[28] Ceriello, A., and Motz, E. 2004. "Is oxidative stress the pathogenic mechanism underlying insulin resistance, diabetes, and cardiovascular disease? The common soil hypothesis revisited." Arteriosclerosis, Thrombosis, and Vascular Biology 24 (5): 816-23.

[29] Visioli, F., and Galli, C. 1998. "Olive oil phenols and their potential effects on human health." Journal of Agricultural and Food Chemistry 46 (10): 4292-6.

[30] Tuck, K. L., and Hayball, P. J. 2002. "Major phenolic compounds in olive oil: metabolism and health effects." The Journal of Nutritional Biochemistry 13 (11): 636-44.

[31] Ross, J. A., and Kasum, C. M. 2002. "Dietary flavonoids: bioavailability, metabolic effects, and safety." Annual review of Nutrition 22 (1): 19-34.

[32] Xiao, J., Ni, X., Kai, G., and Chen, X. 2013. "A review on structure-activity relationship of dietary polyphenols inhibiting $\alpha$-amylase." Critical Reviews in Food Science and Nutrition 53 (5): 497-506.

[33] Wang, J, and Mazza, G. 2002. "Effects of anthocyanins and other phenolic compounds on the production of tumor necrosis factor $\alpha$ in LPS/IFN- $\gamma$-activated RAW 264.7 macrophages." Journal of Agricultural and Food Chemistry 50 (15): 4183-9.

[34] Liu, W., Xu, J., Wu, S., Liu, Y., Yu, X., Chen, J., Tang, X., Wang, Z., Zhu, X., and Li, X. 2013. "Selective Anti-Proliferation of HER2-Positive Breast Cancer Cells by Anthocyanins Identified by High-Throughput Screening." PloS One 8 (12): e81586.

[35] Tsuda, T., Ohshima, K., Kawakishi, S., and Osawa, T. 1996. "Oxidation products of cyanidin 3-O- $\beta$-D-glucoside with a free radical initiator.” Lipids 31 (12): 1259-63.

[36] Oak, M. H., Bedoui, J., Madeira, S. F., Chalupsky, K., and Schini-Kerth, V. 2006. "Delphinidin and cyanidin inhibit PDGFAB - induced VEGF release in vascular smooth muscle cells by preventing activation of $\mathrm{p} 38$ 
MAPK and JNK." British Journal of Pharmacology 149 (3): 283-90.

[37] Kumar, S., Gautam, S., and Sharma, A. 2013. "Identification of Antimutagenic Properties of Anthocyanins and Other Polyphenols from Rose (Rosa centifolia) Petals and Tea." Journal of Food Science 78 (6): H948-54.

[38] Ozturk, G., Ginis, Z., Akyol, S., Erden, G., Gurel, A., and Akyol, O. 2012. "The anticancer mechanism of caffeic acid phenethyl ester (CAPE): review of melanomas, lung and prostate cancers." Eur. Rev. Med. Pharmacol Sci 16 (15): 2064-8.

[39] Ho, Y.-J., Chen, W.-P., Chi, T.-C., Chien, C.-C.C., Lee, A.-S., Chiu, H.-L., Kuo, Y.-H., and Su, M.-J. 2013. "Caffeic acid phenethyl amide improves glucose homeostasis and attenuates the progression of vascular dysfunction in Streptozotocin-induced diabetic rats." Cardiovascular Diabetology 12 (1): 99.

[40] Riccioni, G. 2009. "Carotenoids and cardiovascular disease." Current Atherosclerosis Reports 11 (6): 434-9.

[41] Wolak, T., and Paran, E. 2013. "Can carotenoids attenuate vascular aging?" Vascular Pharmacology 59 (3): 63-6.

[42] Manach, C., Williamson, G., Morand, C., Scalbert, A., and Rémésy, C. 2005. "Bioavailability and bioefficacy of polyphenols in humans. I. Review of 97 bioavailability studies." The American Journal of Clinical Nutrition 81 (1): 230S-42S.

[43] Pham-Huy, L. A., He, H., and Pham-Huy, C. 2008. "Free radicals, antioxidants in disease and health." Int. J.
Biomed Sci 4 (2): 89-96.

[44] Stoner, G. D., Wang, L. S., Seguin, C., Rocha, C., Stoner, K., Chiu, S., and Kinghorn, A. D. 2010. "Multiple berry types prevent N-nitrosomethylbenzylamine-induced esophageal cancer in rats." Pharm. Res. 27 (6): 1138-45. doi: 10.1007/s11095-010-0102-1.

[45] de Souza, M. O., Silva, M., Silva, M. E., Oliveira Rde, P., and Pedrosa, M. L. 2010. "Diet supplementation with acai (Euterpe oleracea Mart.) pulp improves biomarkers of oxidative stress and the serum lipid profile in rats." Nutrition 26 (7-8): 804-10. doi: 10.1016/j.nut.2009.09.007.

[46] Jensen, G. S., Ager, D. M., Redman, K. A., Mitzner, M. A., Benson, K. F., and Schauss, A. G. 2011. "Pain Reduction and Improvement in Range of Motion After Daily Consumption of an Açai (Euterpe oleracea Mart.) Pulp-Fortified Polyphenolic-Rich Fruit and Berry Juice Blend. " Journal of Medicinal Food 14 (7-8): 702-11.

[47] Jensen, G. S., Wu, X., Patterson, K. M., Barnes, J., Carter, S. G., Scherwitz, L., Beaman, R., Endres, J. R., and Schauss, A. G. 2008. "In vitro and in vivo antioxidant and anti-inflammatory capacities of an antioxidant-rich fruit and berry juice blend. Results of a pilot and randomized, double-blinded, placebo-controlled, crossover study." Journal of Agricultural and Food Chemistry 56 (18): 8326-33.

[48] Udani, J. K., Singh, B. B., Singh, V. J., and Barrett, M. L. 2011. "Effects of Acai (Euterpe oleracea Mart.) berry preparation on metabolic parameters in a healthy overweight population: A pilot study." Nutrition Journal 10 (45). 